\title{
REPORT OF A CASE OF PULMONARY TELANGIECTASIA
}

BY

\author{
G. H. APTHORP AND D. V. BATES \\ From the Medical Unit, St. Bartholomew's Hospital, London
}

(RECEIVED FOR PUBLICATION OCTOBER 24, 1956)

Arteriovenous aneurysms in the lung are now well recognized as a cause of central cyanosis and polycythaemia. Since Whitaker in 1947 showed their histology to be identical with the cutaneous lesions of familial haemorrhagic telangiectasia, it has been known-that the pulmonary lesion is but part of a widespread vascular abnormality. The criterion for diagnosis of a pulmonary arteriovenous aneurysm as a cause of central cyanosis is the demonstration of the lesion by angiocardiography. Nearly all the cases described in the literature had vascular abnormalities in other organs.

Four patients have been described, however, in whom this picture was reversed. The central cyanosis was due to telangiectatic dilatation of the small pulmonary vessels in close contact with the alveoli, and the arteriovenous aneurysms, when they existed, were elsewhere in the body. Brink in 1950 described a patient with central cyanosis in whom there was no evidence of intracardiac shunt and the angiocardiogram was normal. In 1954 Cooley and McNamara described a cyanosed patient in whom the diagnosis was proved by lung biopsy, and in the same year Weiss and Gasul described a case of their own and were able to find a further case in the literature. In both these cases the diagnosis was confirmed at necropsy.

The purpose of this paper is to record a fifth case of pulmonary telangiectasia causing central cyanosis and polycythaemia. In this patient the diagnosis was suggested by the findings at cardiac catheterization and the results of pulmonary function tests.

\section{CASE RePort}

An 18-year-old boy was transferred from Addenbrooke's Hospital, Cambridge, in October, 1955, to the Medical Unit at St. Bartholomew's Hospital for investigation of central cyanosis. $\mathrm{He}$ had had a normal childhood, but three years before admission noticed cyanosis of the tongue and lips. At first the cyanosis was not associated with effort dyspnoea and he continued to work as a farm labourer. A few months before admission he became slightly short of breath on severe exertion. He had no symptoms suggestive of respiratory disease or cardiac failure.
He also gave a history of recurrent severe nose bleeds and two large haematemeses. After one of these haematemeses in 1954 he had been investigated at Papworth Hospital. He was found to be polycythaemic at that time, but tomography of the lung and angiocardiography were normal. The barium swallow showed oesophageal varices. Nine months before admission a splenectomy had been performed at Addenbrooke's Hospital for persistent thrombocytopenia, the platelet count being 50,000 per c.mm. At operation the spleen was found to be congested, and the portal pressure was $255 \mathrm{~mm}$. of saline. The liver was seen to contain a number of dark red nodules, and biopsy showed that these were composed of normal liver tissue lying between grossly dilated portal venules, the appearances being those of haem-

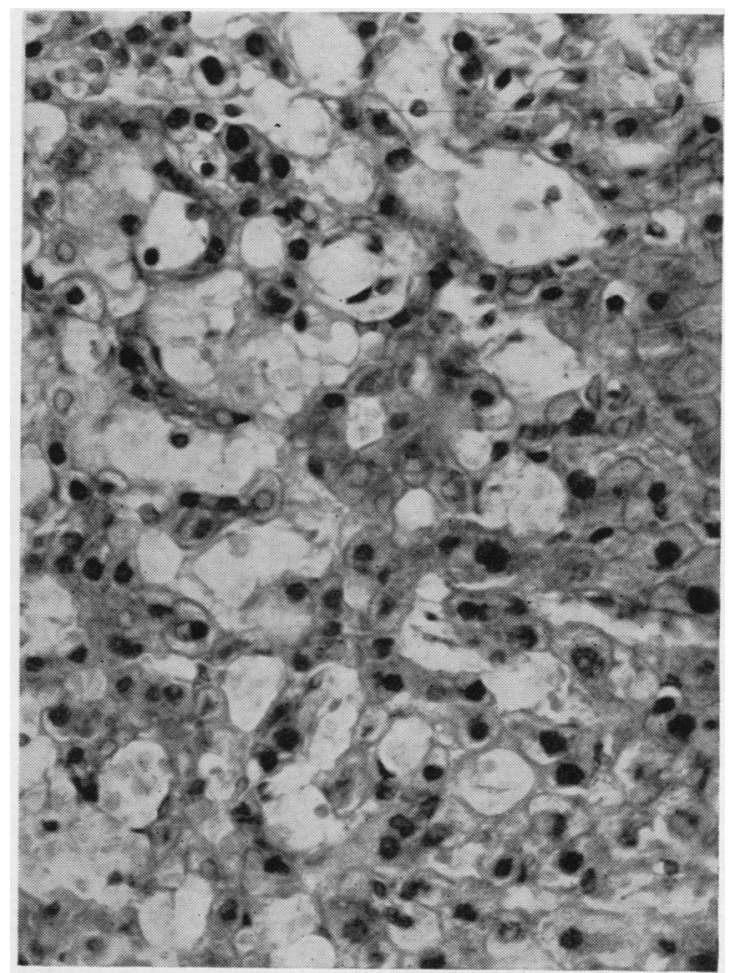

FIG. 1.-Photomicrograph of biopsy of the liver showing widely dilated vascular channels and abnormal small vessels forming haemangioma. Haematoxylin and eosin, > 210. 


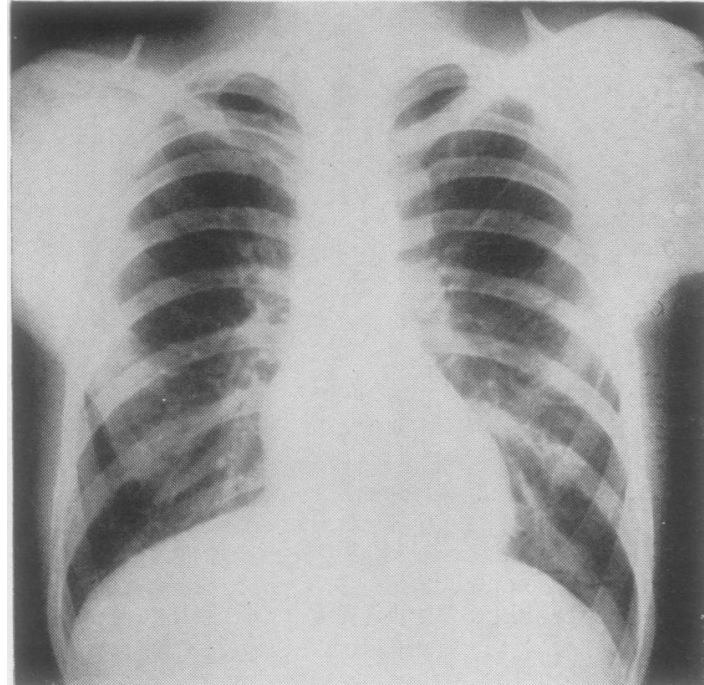

FIG. 2.-Radiograph of the chest.

angiomata of the liver (Fig. 1). No evidence of cirrhosis was found, and it was thought that the naemangiomata were acting as arteriovenous fistulae resulting in portal hypertension and oesophageal varices. Since splenectomy the platelet count had remained low, but no more bleeding incidents had occurred.

Examination showed an intelligent, normal-sized boy of 18 years with cyanosis of the lips and tongue, and severe clubbing and cyanosis of the fingers and toes. There were dilated venules in the skin, most prominent between the shoulder-blades, and two pin-sized haemangiomata on the neck and left thumb. The lungs were normal to clinical examination. The radial pulse was normal, and the blood pressure was 120 / $70 \mathrm{~mm}$. $\mathrm{Hg}$ in both arms. The jugular venous pressure was not raised. There was no cardiac enlargement and no clinical evidence of ventricular hypertrophy. The heart sounds were normal. There was a soft murmur loudest in systole, running through the second sound and ending in mid-diastole, best heard at the pulmonary area and over the left lung root posteriorly. Its intensity was increased by leaning the patient forward and by the Mueller manœuvre, but was not affected by the Valsalva manœuvre. The liver was not enlarged and there was no hepatic bruit. The limbs apart from clubbing and cyanosis; were normal.

Blood investigations were as follows: Haemoglobin, $118 \%$ Haldane (17.5 g. per $100 \mathrm{ml}$.) ; erythrocytes, 6.5 million per c.mm.; packed cell volume, $52.5 \%$; platelets, 96,000 per c.mm.; leucocytes, 6,500 per c.mm. with a normal differential count; blood film, normal.

The sternal marrow was normal, with no evidence of megakarocyte maturation defect. No abnormal blood pigments were found. Liver-function tests were normal. The urine contained no bile pigments. The blood chemistry was normal.
Postero-anterior radiography of the chest (Fig. 2) and lateral tomograms showed no abnormality. Screening showed a heart of normal overall size but $\overline{\bar{\sigma}}$ with evidence of right ventricular enlargement in the $\overline{\bar{S}}$ oblique views. The electrocardiogram showed the $\mathbb{\Phi}$ pattern of right ventricular hypertrophy.

The results of cardiac catheterization are sum- $ळ$ marized in Table $I$, and show that the pressures in $\overrightarrow{0}$ the right atrium, right ventricle, and pulmonary artery $\rightarrow$

\begin{tabular}{|c|c|c|c|c|}
\hline & & $\begin{array}{l}\text { Systolic and } \\
\text { Diastolic } \\
\text { Pressure } \\
\text { (mm. Hg) }\end{array}$ & $\begin{array}{c}\text { Mean } \\
\text { Pressure } \\
\text { (mm. Hg) }\end{array}$ & $\begin{array}{l}\text { Oxygen } \\
\text { Content } \\
\text { (Vol. \%) }\end{array}$ \\
\hline $\begin{array}{l}\text { Pulmonary capillary } \\
\text { artery } \\
\text { Righ" ventricle ... } \\
\text { Superior vena cava } \\
\text { Femoral artery }\end{array}$ & & $\begin{array}{l}5 /-3 \\
10 / 0 \\
25 / 0 \\
\overline{1} \overline{120 / 70}\end{array}$ & $\begin{array}{r}2 \\
4 \\
5 \\
-3 \\
90\end{array}$ & $\begin{array}{l}1 \overline{14 \cdot 5} \\
14 \cdot 6 \\
14 \cdot 3 \\
14 \cdot 3 \\
16 \cdot 6\end{array}$ \\
\hline
\end{tabular}

are in each case lower than the corresponding left $\mathcal{G}$ atrial ("pulmonary capillary"), left ventricular, and * aortic pressures, and thus exclude a right-to-left shunt as a cause of the central cyanosis. The superior and inferior venae cavae were shown to enter the right $\bar{\partial}$ atrium normally. The femoral arterial blood during cardiac catheterization was $81 \%$ saturated only.

Angiocardiography carried out at the National Heart Hospital, using a technique allowing films to $\overrightarrow{\overrightarrow{0}}$ be taken at very short intervals, showed an abnormal 3 vascular pattern with dilatation of the small vessels and late emptying of small scattered rounded areas suggestive of these being dilated venous sinuses (Fig. 3).

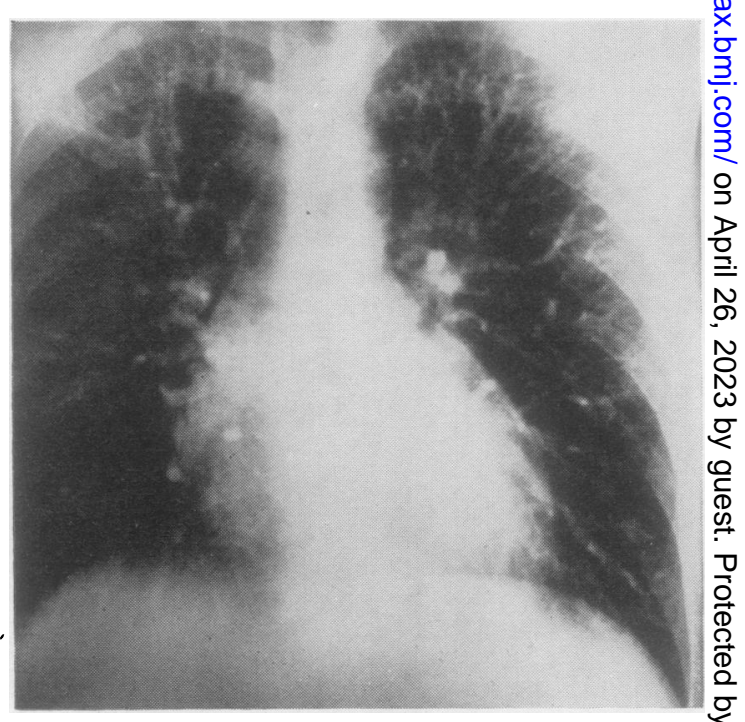

FIG. 3.-Angiocardiogram showing abnormal vascular pattern and late emptying of some peripheral vessels. 
TABLE . I

PULMONARY FUNCTION TESTS

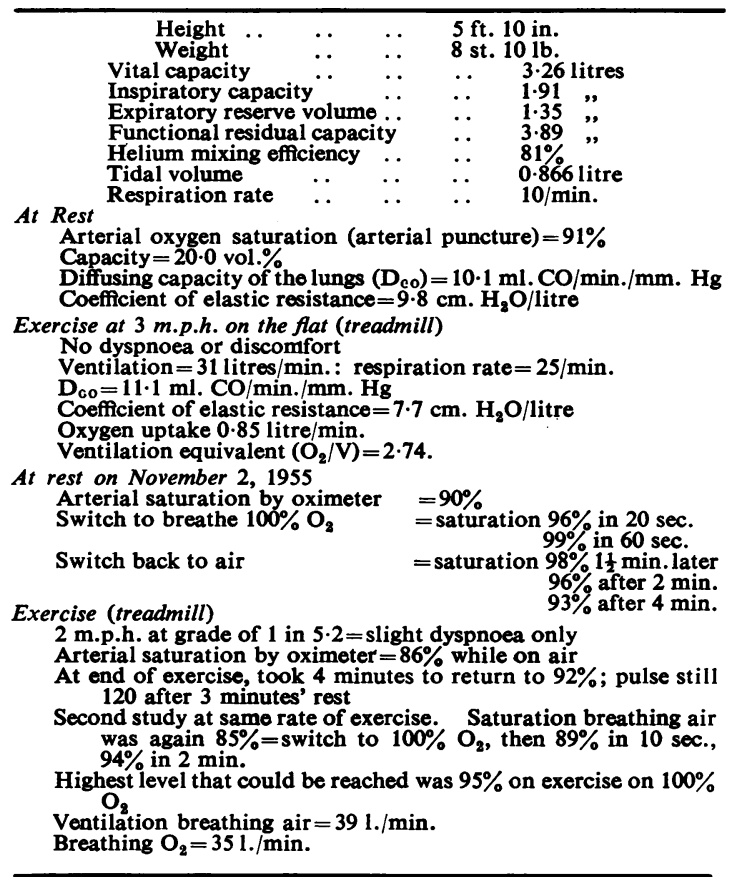

The results of the pulmonary function tests are shown in Table II. They are interpreted as follows.

The ventilatory aspects of pulmonary function are normal, and there is no increased stiffness of the lung: this accounts for the striking absence of dyspnoea even on severe exercise. The only rather unusual value is the F.R.C., which is about $600 \mathrm{ml}$. larger than one would have predicted.

The resting diffusing capacity of the lungs is at the lower limit of normal values (Bates, Boucot, and Dormer, 1955). On the degree of exercise which he did, this should have increased to about $32 \mathrm{ml}$. CO/ $\mathrm{min} . / \mathrm{mm}$. $\mathrm{Hg}$, whereas it only changed from 10 to 11 . This is clearly an abnormal finding, and indicates that the effective blood surface area exposed to gas in the lungs does not increase on exercise. Either there is no increase in alveolar perfusion on exercise, or the blood passing through the lungs is for some reason not being exposed to the gas normally. The normal resting value makes a primary membrane diffusion defect most unlikely.

During exercise ventilation rose out of proportion to oxygen consumption (low ventilation equivalent), presumably due to anoxic stimulation of the respiratory centre.

The immediate increase in arterial saturation to $99 \%$ when the patient breathed $100 \%$ oxygen indicates that a sixfold increase in oxygen pressure in the alveoli enables oxygen to pass into blood which would otherwise remain unsaturated. The fact that the saturation cannot be made to reach $99 \%$ on exercise indicates that, with the increased blood flow in the lungs during exercise, blood is passing through that cannot be oxygenated even by $100 \%$ oxygen.

This unusual combination of results can only satisfactorily be explained by blood passing through greatly widened lung capillaries, in which part of it does not become fully saturated. On exercise the pulmonary blood flow increases, but the surface area exposed to alveolar gas does not increase, and hence the diffusing capacity does not change. The arterial oxygen saturation consequently drops further. However, when the patient breathes $100 \%$ oxygen at rest the blood rapidly becomes fully saturated, indicating that the previously unsaturated blood must be passing in close proximity to the alveolar gases. During exercise, while breathing $100 \%$ oxygen, the raised alveolar oxygen tension is unable to maintain full saturation in the presence of increased blood flow without a corresponding increase in surface area, and arterial saturation falls again. Such a situation in the lung might be found if there were multiple telangiectases such as are present in the liver and in the skin. If one large shunt were present, one would find only a very slight increase when the patient breathed $100 \%$ oxygen.

Of the four previously reported cases of pulmonary telangiectasia, the diagnosis was confirmed by lung biopsy in one and by necropsy in two. In the first case reported in 1950 by Brink the diagnosis was not proved.

In our patient the results of cardiac catheterization exclude a cardiac cause of the central cyanosis. It is most unlikely that the low pulmonary artery pressure is due to stenosis of the pulmonary valve, as the right ventricular pressure is normal. The pressure gradient is accounted for by enlargement of the pulmonary vessels in association with a low peripheral resistance due to telangiectatic dilatation of the small pulmonary vessels. Greene, Baldwin, Baldwin, Himmelstein, Roh, and Cournand (1949) described a similar phenomenon in idiopathic dilatation of the pulmonary arteries.

\section{SUMMARY}

An 18-year-old boy, known to have multiple haemangiomata of the liver, developed central cyanosis and polycythaemia. Evidence that these were due to pulmonary telangiectasia was provided by the results of detailed pulmonary function tests and cardiac catheterization, supported by angiocardiography.

We wish to thank Dr. A. P. Dick, of Addenbrooke's Hospital, Cambridge, for referring the patient to us for investigation, and Dr. G. W. Hayward for help and encouragement in writing this paper.

\section{REFERENCES}

Bates, D. V., Boucot, N. G., and Dormer, A. E. (1955). J. Physiol. (Lond.), 129, 237.

Brink, A. J. (1950). Quart. J. Med., n.s., 19, 239.

Cooley, D. A., and MeNamara, D. G. (1954). J. thorac. Surg., 27, 614.

要, Baldwin, E. De F., Baldwin, J. S., Himmelstein, A. Weiss, E., and Gasul, B. M. (1954). Ann. intern. Med., 41, 989. Whitaker, W. (1947). Thorax, 2, 58. 